\title{
LA-UR-21-28705
}

Approved for public release; distribution is unlimited.

Title: Happy Fall today, from 1959

Author(s): $\quad$ Steeves, Brye Ann

Intended for: Web

Issued: 
Disclaimer:

Los Alamos National Laboratory, an affirmative action/equal opportunity employer, is operated by Triad National Security, LLC for the National Nuclear Security Administration of U.S. Department of Energy under contract 89233218CNA000001. By approving this article, the publisher recognizes that the U.S. Government retains nonexclusive, royalty-free license to publish or reproduce the published form of this contribution, or to allow others to do so, for U.S. Government purposes. Los Alamos National Laboratory requests that the publisher identify this article as work performed under the auspices of the U.S. Department of Energy. Los Alamos National Laboratory strongly supports academic freedom and a researcher's right to publish; as an institution, however, the Laboratory does not endorse the viewpoint of a publication or guarantee its technical correctness. 


\section{Happy Fall today, from 1959}

By the National Security Research Center staff

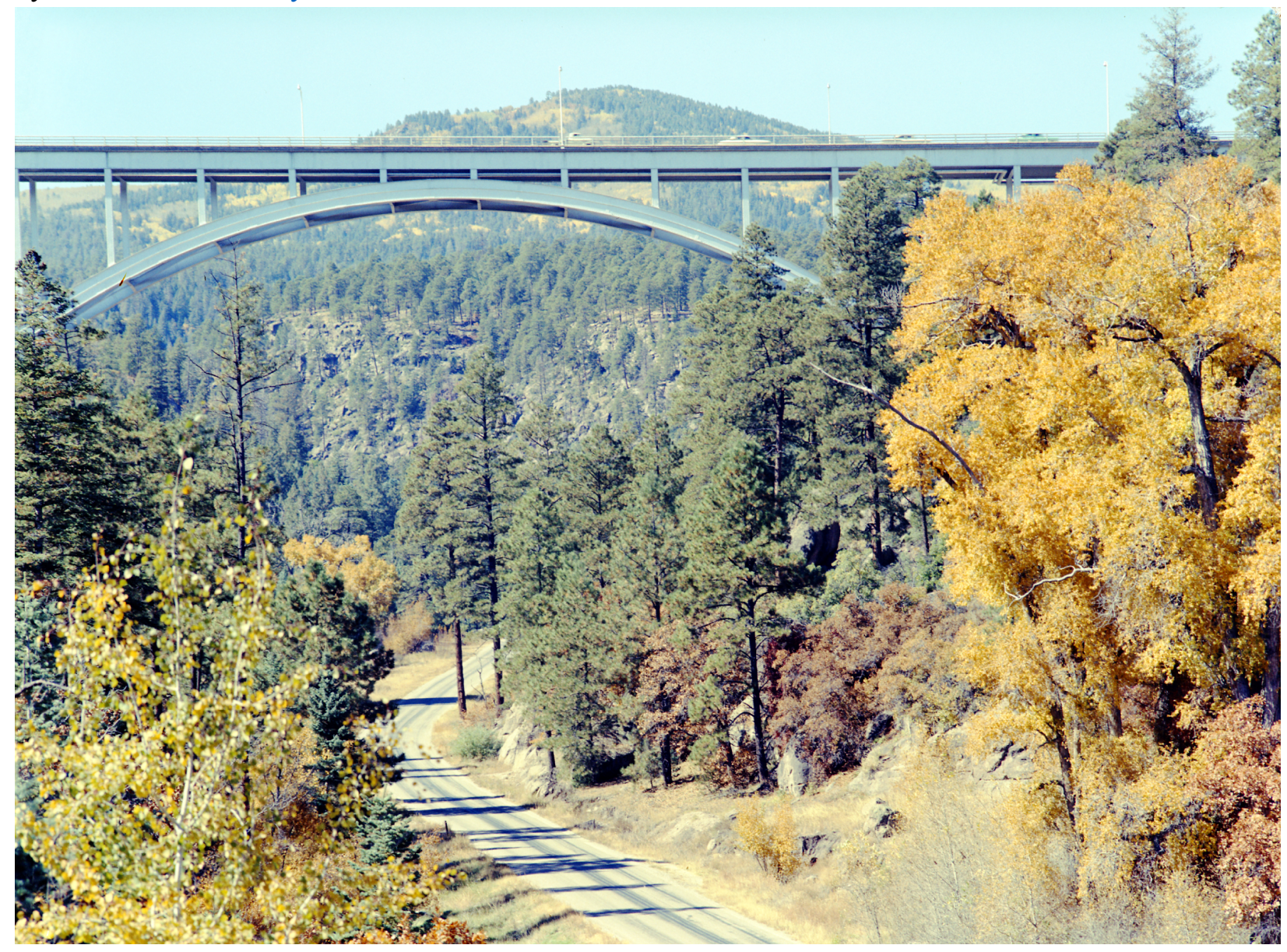

photo location:

https://drive.google.com/file/d/14XRr6ZahL5yp09_2MOJ4PabUcdgY51Oo/view?usp=sharing

Pumpkin spice everything, college football and changing leaves.

The signs are everywhere and today (Wednesday, Sept. 22) marks the first official day of fall.

This throwback photo of the Omega Bridge is from the fall of 1959. The bridge was completed in 1951, among many other infrastructure projects needed to continue the Lab's shifting national security mission after the end of World War II.

Years earlier, in the fall of 1942, Los Alamos was chosen as the site for the then-secret lab to create the world's first atomic bombs. Wartime director J. Robert Oppenheimer suggested the location because he had visited the area as a young man and was familiar with its remote and beautiful setting.

Photos like these are part of the collections of the National Security Research Center, which houses unclassified artifacts from the Lab's history as well as classified nuclear weapons-related materials for today's work. Contact us at nsrc@lanl.gov. 